\title{
Práticas ed ucacionais em instituições de Educação Especial no estado de Sergipe (1962-1987)
}

\author{
Educational practices in special education institutions in the state of Sergipe (1962-1987)
}

\author{
Walna Patrícia de Oliveira Andrade* \\ Joaquim Tavares da Conceição**
}

\author{
Palavras chave: \\ Instituições educativas \\ Memórias \\ Práticas educacionais
}

\begin{abstract}
Resumo: Esta pesquisa tem como objeto a história de práticas educacionais realizadas em instituições de educação especial sergipanas, no período entre 1962 e 1987 . O objetivo foi analisar práticas educacionais relacionadas às pessoas com deficiência, no período do recorte temporal pesquisado. Metodologicamente, esta é uma pesquisa histórica, na perspectiva da História Cultural, buscando aporte teórico em Chartier (1988); de cunho documental e conjugada com a História Oral Temática, pautada em Meihy e Holanda (2015), por meio de narrativas obtidas em entrevistas. A pesquisa utiliza como fonte nove entrevistas, destas, oito foram realizadas pela autora, estatutos e livro de atas coletados nas instituiçóes pesquisadas, além de jornais. Constatou-se que as práticas educacionais realizadas nas instituições ocorriam, na maioria dos casos, pautadas num modelo denominado pelas professoras de "intuitivo", neste, a partir dos resultados obtidos, davam-se novos direcionamentos aos trabalhos.
\end{abstract}

Abstract: This research has as an object the history of educational practices held at special education institutions from Sergipe, between 1962 and 1987. The objective was to analyse educational practices related to the people with disabilities, during the period of the temporal cut researched. Methodologically, this is a historical research, from the perspective of the Cultural History, seeking theoretical contribution in Chartier (1988); of documental nature and conjugated with the Thematic Oral History, grounded on Meihy and Holanda (2015), through narratives obtained in interviews. The research uses nine interviews as a source, out of these ones, eight were conducted by the author, statutes and book of minutes collected at the researched institutions, besides newspapers. It was observed that the educational practices held at the institutions occurred, in most cases, grounded on a pattern called "intuitive" by the teachers, in this one, from the outcomes obtained, new directions to the works were provided.

Recebido em 20 de outubro de 2020. Aprovado em 29 de março de 2021.

\footnotetext{
* Mestra em Educação pela Universidade Federal de Sergipe (UFS). Integra o Grupo de Estudos e Pesquisas em História da Educação Memórias, Sujeitos e Práticas Educativas (Gephed/CNPq/UFS). E-mail: walnaandrade77@gmail.com.

ORCID: https://orcid.org/0000-0001-6636-3347

** Doutor em História pela Universidade Federal da Bahia (UFBA). Integra o Programa de Pós-Graduação em Educação da Universidade Federal de Sergipe; e lidera o Grupo de estudos e pesquisas em História da Educação: Memórias, sujeitos, saberes e práticas educativas (Gephed/Cnpq/UFS). E-mail: joaquimcodapufs@gmail.com.

ORCID: https://orcid.org/0000-0002-8826-8137
} 


\section{Introd ução}

Este artigo disserta sobre a história de práticas educacionais realizadas em instituiçôes de educação especial, no período entre 1962 e 1987, em Sergipe. A delimitação temporal teve como marco inicial o ano de 1962, quando foi fundada a primeira instituição sergipana que recebeu pessoas com deficiência. O marco final foi o ano de 1987, quando a Associação de Amigos do Autista de Sergipe (Amas) foi fundada. Essa instituição foi, por muitos anos, referência estadual quanto ao seu trabalho educacional direcionado às pessoas com autismo.

A pesquisa foi realizada com a colaboração de pais, professoras, fundadores e funcionários das instituiçốes pesquisadas, que se deu por meio do consentimento de entrevistas e da possibilidade de acesso ao acervo documental. Importante salientar que no período em que as professoras entrevistadas trabalharam nas referidas instituiçôes, a maioria tinha formação em nível médio, obtida nas já extintas "escolas normais", que foram, de acordo com Silva e Rodrigues (2018), instituições responsáveis pela formação de professores entre a segunda metade do século XIX e durante o século XX.

No decorrer das entrevistas, buscaram-se dados que elucidaram como era o trabalho pedagógico realizado pelos professores nessas instituições e quais práticas o norteavam. Só foram utilizadas as iniciais dos nomes dos entrevistados, como forma de proteger suas identidades. Por se tratar de um estudo no qual foram envolvidos seres humanos, necessitou de aprovação do Comitê de Ética em Pesquisa da Universidade Federal de Sergipe. Ressalta-se, por conseguinte, que esta pesquisa foi conduzida de acordo com os padróes éticos exigidos e sua aprovação teve como comprovação o seguinte número do protocolo: 3.570.023.

Os levantamentos documentais aconteceram nas seguintes instituições: Associação de Amigos do Autista de Sergipe (Amas), Associação de Pais e Amigos do Excepcional (Apae) e Sociedade de Ensino e Reabilitação Rosa Azul (atualmente o nome desta instituição é Centro de Integração Raio de Sol). No Centro de Reabilitação Ninota Garcia não foi encontrado nenhum documento do período pesquisado, contudo foram entrevistadas pessoas que fizeram parte dele, como professores e pais de alunos, além de terem sido pesquisadas e analisadas outras fontes importantes, como o livro escrito pelo fundador da instituição, o médico Antônio Garcia Filho, que trata especificamente sobre a instalação, manutenção, desenvolvimento e prestígio do local. Todos os documentos encontrados foram catalogados de acordo com a relevância na construção do trabalho.

\section{A ed ucabilidade das pessoas com deficiência}

Os debates sobre a educabilidade da pessoa com deficiência advêm do século XVIII, para os deficientes sensoriais (surdos e cegos), e do século XIX para os deficientes intelectuais, porém, eram iniciativas isoladas. Só no início do século XX ganha $o$ interesse $\mathrm{da}$ sociedade a possibilidade do desenvolvimento e aprendizagem das pessoas com deficiência (JANNUZZI, 2012). Desse período é originária a defectologia, que tem como um dos seus principais precursores Lev S. Vygotsky. O termo defectologia refere-se ao estudo de crianças com alguma deficiência, nesse momento conhecido como um "defeito", podendo ser este físico ou intelectual. Quanto à compreensão da inexistência de teorias criadoras, forma pela qual poderia ser considerada a defectologia, Chartier (1988) alerta:

[...] não existem, no sentido próprio do termo, 'teorias criadoras', porque desde o momento em que uma ideia, por mais fragmentária que seja, se realizou no domínio dos factos, da maneira mais imperfeita que se queira, não é a ideia que conta a partir de então, é a instituição colocada no seu lugar, no seu tempo, incorporando uma rede complicada e móvel de factos sociais, que produzem e sofrem regularmente mil acções diversas e mil reações (CHARTIER, 1988, p. 33).

Compactuando com Chartier (1988), analisamos os estudos de Vygotsky, que representavam uma ação geradora de muitas reações, no sentido de que arbitrariamente ao que era difundido no início do século $\mathrm{XX}$, não se baseavam na questão das dificuldades apresentadas e sim nas 
potencialidades presentes em cada pessoa. Seu interesse principal era transformar o modo pelo qual a deficiência era compreendida, focada apenas nas limitaçóes oriundas do fator biológico. Isso não significava que a base orgânica não fosse percebida pelo estudioso, porém seu maior argumento consistia na importância dos estímulos recebidos por intermédio do meio social para a aprendizagem ser consolidada. Esses estudos trouxeram grandes contribuiçóes para a Educação Especial. De acordo com Vygotsky (1997), a pessoa nasce somente com os seus recursos biológicos, todavia sua convivência social concretiza seu processo de humanização, principalmente mediante o ensino e a aprendizagem. Mas devido à forte influência da medicina, com seu enfoque terapêutico, a escola já recebia os alunos estigmatizados pelas suas limitaçôes, sendo-lhes negada a possibilidade da tentativa de desenvolvimento dos seus potenciais por meio de atividades que os privilegiassem.

Cualquer persona comprende que no hay nada más indeseable que la selección de acuerdo com lãs particularidades negativas. Cuando realizamos esta selección nos arriesgamos a separar y a unir em un grupo de niños que tendrán poço em común em el aspecto positivo [...] (VYGOTSKY, 1997, p. 101).

Considerava, assim, essa situação uma forma de seleção com a qual ficavam separados os alunos que poderiam e os que não poderiam participar do ensino regular, tendo estes últimos como única opção a instituição de educação especial.

A defectologia, na perspectiva Vygotskyana, trata fundamentalmente das questôes relacionadas à aprendizagem da pessoa com qualquer tipo de deficiência. No que se refere à deficiência intelectual, Vygotsky (1997) nos diz que o seu desenvolvimento não é diferente daquelas com outro tipo de "defeito", e que a própria deficiência acaba estimulando tanto o organismo quanto a personalidade a desencadear processos compensatórios que nivelam a deficiência, tornando essa pessoa mais ativa ao meio, o que nos apresenta a possibilidade de sua educabilidade por meio de estudos científicos.

Contudo, buscando na história como se dava especificamente $\mathrm{o}$ atendimento educacional destinado às pessoas com deficiência, percebe-se que na maioria dos casos o que se observa é uma prevalência $\mathrm{da}$ abordagem clínica sobre a educacional. Segundo Jannuzzi (2012), a vinculação da educação das pessoas com deficiência ao campo da medicina acontece desde os seus primórdios, no século XVI. No Brasil podemos considerar do início da segunda metade do século XIX, quando essa acontecia em escolas anexas aos hospitais psiquiátricos e instituiçóes especializadas. No que se refere à produção teórica, os médicos foram os pioneiros, logo seguidos pelos pedagogos influenciados pela psicologia. Os "vultos" mais citados pelos escolanovistas no Brasil eram os médicos e educadores Ovide Decroly e Maria Montessori, que fizeram um trabalho educacional com os considerados "anormais". Decroly, em 1901 no instituto para retardados, e Montessori, que se formou em medicina em 1894 e por um tempo dedicou-se à preparação de professores primários em Roma, pautada nos ensinamentos de Séguin e no conhecimento que obteve sobre o trabalho de Itard, na Escola Normal Ortofrênica que ela fundou.

O despertar dos médicos nesse campo educacional pode ser interpretado como procura de respostas ao desafio apresentado pelos casos graves, resistentes ao tratamento exclusivamente terapêutico, quer no atendimento clínico particular, quer no, muitas vezes, doloroso encontro de crianças misturadas às diversas anomalias nos locais que abrigavam todo tipo de doentes, inclusive os loucos (JANNUZZI, 2012, p. 27).

Visando retirar a hegemonia discursiva da medicina, passaram a ser difundidas outras teorias como da Psicologia, da Sociologia e da Antropologia, as quais promoveram importantes contribuiçóes para esse campo. Em meados do século XX começaram a surgir, em vários países, questionamentos com relação ao paradigma médico de se compreender a deficiência, trazendo discussóes sobre a importância social no tratamento das questóes vivenciadas por essas pessoas. Neste sentido, a deficiência deixa de ser responsabilidade individual e passa a ser uma questão social. Com as discussões sobre a necessidade de ser superada a visão médica, esta foi sendo gradualmente substituída pela 
Psicologia e pela Pedagogia, especialmente pela ação do educador Norberto Souza Pinto, e pela natureza psicológica dos trabalhos da educadora Helena Antipoff. Acontecia, nesse momento, o que Chartier (1988) denomina como a passagem de um sistema de representação a outro, no qual, além de uma ruptura radical nos saberes e nas estruturas do pensamento, configura-se um processo permeado por hesitaçóes, retrocessos e bloqueios.

Mesmo não existindo uma negação quanto à possibilidade de educação das pessoas com deficiência, muitas não puderam participar do sistema educacional devido a ser creditada a essas a impossibilidade de aprender. Em Sergipe, a educação dessas pessoas esteve sempre ligada ao processo de institucionalização da educação especial. Essa inicia-se a partir da década de 1960, com incentivos federais para a criação de instituições voltadas para este objetivo. Em 1970, tem-se a institucionalização das salas especiais, por meio da Secretaria de Educação do Estado de Sergipe, em consonância com diretrizes e verbas federais.

Das práticas emendativas e segregadas das instituiçôes especiais ao ensino normalizador das classes especiais, os caminhos das crianças e adolescentes ocorreram sem diálogos entre os dispositivos educacionais e revelaram uma constante produção da anormalidade no meio escolar (com o viés da dificuldade de aprendizagem) e a negação deste meio para os casos graves (idiotas e doentes mentais) (MINATEL, 2018, p. 158).

No início da década de 1980, todos aqueles que fugiam da normalidade instituída eram considerados excepcionais, sendo que não se acreditava muito na possibilidade de educação dessas pessoas. Neste sentido, pode-se dizer que as sociedades estabelecem meios de caracterizar as pessoas a partir de atributos comuns e naturais para os membros e grupos que delas fazem parte. Por meio desta classificação, os ambientes sociais estabelecem as probabilidades dos limites e possibilidades que podem ser mensurados. Assim, as rotinas presentes nas relações sociais, em ambientes estabelecidos, permitem relacionamentos sem atenção ou reflexão particular. Seguindo esta perspectiva, podemos compreender que essas pessoas eram classificadas por meio de um estigma, entendido como:

\begin{abstract}
Um atributo profundamente depreciativo, mas o que é preciso, na realidade, é uma linguagem de relações e não de atributos. Um atributo que estigmatiza alguém pode confirmar a normalidade de outrem [...].(GOFFMAN, 1988, p. 06).
\end{abstract}

Entende-se então que um estigma é concebido como uma relação entre atributo e estereótipo, embora Goffman também sugira que haja modificação quanto a este conceito, visto que existem atributos que algumas sociedades desqualificam.

\section{Conhecendo algumas instituições de educação especial sergipanas e suas práticas educacionais}

A instituição pioneira no trabalho com a Educação Especial neste estado foi o Centro de Reabilitação Ninota Garcia, fundado pelo médico Antônio Garcia Filho, sendo a terceira instituição no Brasil voltada para este tipo de educação. Tal fato demonstra que o estado de Sergipe foi um dos primeiros da federação a se preocupar com a educação dos chamados "excepcionais". O Centro foi fundado no dia 24 de junho de 1962, no Bairro Industrial, e tinha como presidente a primeira dama do Estado na época, Emília Marques Garcia, cunhada do fundador da instituição e conhecida como "Ninota Garcia". De acordo com Antônio Garcia, a instituição tinha:

O ensino em Jardins de Infância, pré-primário e primário nos seus diversos ramos de classes, trabalhos manuais, artes industriais (cerâmica, madeira, metal, cestaria, couro, tapeçaria, mosaico, desenho, cartazes, etc.) ou especializado (cegos, surdos-mudos, excepcionais), embutidos num Centro de Reabilitação, dêle fazendo parte integrante [...] (GARCIA FILHO, 1966, p. 48).

O Centro foi considerado uma das mais importantes obras realizadas pelo governador Luiz Garcia, sendo que estava inscrita na placa comemorativa de inauguração a frase: "Aqui renasce 
a esperança”, o que demonstra a expectativa gerada pela criação dessa instituição na educação e reabilitação das pessoas com deficiência (INAUGURADO FESTIVAMENTE... Correio de Aracaju, 1962, p. 01). Antônio Garcia Filho dirigiu a instituição durante toda sua primeira década de existência, aplicando nela seu conhecimento médico e científico. O Ninota Garcia era mantido por meio de convênios estabelecidos com a Secretaria de Educação, Cultura e Saúde e de doações da União Sergipana de Assistência, além de diversos tipos de donativos. Era muito bem planejado e estruturado, sendo que o irmão de Antônio Garcia, Luiz Garcia, que era o governador de Sergipe nessa época, possibilitou que o Centro pudesse adquirir modernos aparelhos, além da capacitação de funcionários.

Conforme Garcia Filho, o pessoal técnico foi preparado e a aparelhagem cuidadosamente estudada e selecionada para promover o bem-estar da população. Além disso, ele visitou os Centros de Reabilitação existentes no país na época, localizados em Recife, Salvador, Rio de Janeiro, São Paulo e Brasília (este estava em construção), tendo contato com os técnicos no assunto e participado de alguns encontros referentes à reabilitação de pessoas com deficiência. "A Secretaria de Educação, Cultura e Saúde, proporcionou, total ou parcialmente, cursos e estágios aos futuros técnicos e educadores" (GARCIA FILHO, 1966, p. 12).

Essa instituição foi criada com a finalidade de assistir deficientes motores e sensoriais. "A assistência era gratuita, dispunha de fisioterapia, reabilitação e educação para os cegos, surdos e mudos" (SOUZA, 2000 , p. 122). Os atendidos, de modo geral, faziam parte de um público diversificado, com variada faixa etária e oriundo de diversos municípios de Sergipe. O Ninota Garcia, em 1962, tinha um jardim de infância, destinado às crianças carentes da comunidade, e dentre estas existiam alunos com deficiência, porém, em quantidade reduzida. No ano seguinte, em 1963, tinha uma "Escola Primária" que atendia alunos entre seis e 14 anos, entre os quais havia alunos com deficiência física e "deficitários mentais". Havia uma escola para a educação de surdos e outra para a educação de cegos (Escola Lions Clube), com conteúdos específicos que "[...] foram cuidadosamente selecionados e adaptados para o processo de aprendizagem daqueles que apresentavam dificuldades auditivas, visuais, motoras e intelectivas" (SILVA, 2012, p. 147). O número de "deficitários mentais" (termo utilizado na década de 1960 para designar as pessoas com deficiência intelectual) aumentou sensivelmente entre os anos de 1962 e 1965. Em 1962 não é apresentada nenhuma pessoa com essa deficiência, mas nos anos de 1963 e 1964 já são atendidas três pessoas e no seguinte aumenta para dez o número de acompanhados com esse diagnóstico (GARCIA FILHO, 1966). Este aumento aconteceu com todos os tipos de deficiência, o que pode ser justificado devido ao trabalho pioneiro oferecido pela instituição.

No decorrer das pesquisas relacionadas às instituiçôes de educação especial em Sergipe na década de 1980, outro nome sempre citado nas entrevistas foi a da Associação de Pais e Amigos dos Excepcionais (Apae). Esta instituição tem um trabalho com pessoas com deficiência intelectual em vários estados do Brasil, principalmente com as pessoas com Síndrome de Down. A Apae sempre se destacou no Brasil por seu pioneirismo. A primeira instituição do país foi fundada no dia 11 de dezembro de 1954, no Rio de Janeiro.

A primeira reunião do Conselho Deliberativo ocorreu em março de 1955, na sede da Sociedade de Pestalozzi do Brasil. Esta colocou à disposição parte de um prédio, para que instalassem uma escola para crianças excepcionais, conforme desejo do professor La-Fayette Côrtes. A entidade passou a contar com a sede provisória onde foram criadas duas classes especiais, com cerca de vinte crianças (MAGALHÃES et al., 1997, p. 01).

Entre os anos de 1954 e 1962, outras Apaes foram sendo fundadas no país, e no final de 1962 já existiam 16 instituições, 12 só em São Paulo. Em Sergipe, a primeira Apae foi inaugurada no dia $27 \mathrm{de}$ agosto de 1968, no município de Aracaju. No começo as aulas aconteceram em uma sala no Estádio Lourival Batista, não havendo separação dos alunos nem por deficiência nem por idade. Os professores nesse período não tinham conhecimento sobre como realizar um trabalho relevante com pessoas com deficiência, por conta disso alguns foram enviados para a Apae do Rio de Janeiro, onde 
passaram cinco meses estagiando e obtendo formação na Educação Especial. Após esse primeiro momento, os professores passaram por muitas outras capacitações, inclusive dentro da própria instituição.

A Apae de Aracaju cresceu muito por causa da demanda que começou a receber, e em 1973 passou a prestar seus serviços em uma casa alugada na rua de Arauá, mais espaçosa e confortável. "A partir daí, o perfil do público que frequentava a instituição mudou e passaram a ser atendidas pessoas com grande comprometimento e de baixa renda" (MENDONÇA; SOUZA, 2018, p. 48). Em 1979, receberam a doação de um terreno de 2.200 metros quadrados na rua Manoel dos Santos Carvalho, bairro Industrial, sendo então construída a sede própria. Como todas as outras instituições pesquisadas, o maior problema citado nas entrevistas referia-se às dificuldades financeiras, muitas vezes decorrentes dos períodos em que as verbas públicas sofreram descontinuidades.

Outra instituição criada para atender pessoas com deficiência foi a Sociedade de Ensino e Reabilitação Rosa Azul. Esta foi fundada em 9 de agosto de 1979 pela norte-americana CC, nascida na Califórnia e formada em Terapia Ocupacional pela Boston University. CC veio morar no Brasil por intermédio do programa Voluntários da Paz. Na época esse programa estava enviando pessoas para a África e para o Brasil. Ela escolheu o Brasil porque queria aprender a língua portuguesa. O nome "Rosa Azul" foi escolhido por causa de um poema de que CC gostava muito e comparava as crianças a rosas de várias cores, inclusive a rosa $\mathrm{da}$ cor azul. $\mathrm{O}$ poema também traz que “[...] a criança com deficiência é tão bonita quanto as outras crianças, só que precisa de mais cuidado, é muito delicada” (CC, 23/05/2019).

As atividades dessa instituição foram iniciadas na avenida João Ribeiro, bairro Santo Antônio, com 100 assistidos, desses, 45 eram crianças, sendo que em 1989 o número de crianças assistidas já era de 260. No ano de 1980, a Rosa Azul já contava na sua equipe com profissionais pertencentes aos ramos da terapia ocupacional, neuropediatria, psiquiatria, fonoaudiologia, fisioterapia, professores e auxiliares técnicos especializados (Diário de Aracaju, 1980; Tribuna de Aracaju, 1980). Depois foi transferida para a rua Francisco Portugal (1982) e avenida
Tancredo Neves (1985), numa chácara alugada, conhecida como Chácara Asa Branca. No período em que a Rosa Azul funcionou nesse local, segundo sua fundadora, a instituição estava “a todo vapor”. Havia um galpão com oito salas de aula e trabalhavam nela aproximadamente 20 professores, a maioria deles foram cedidos pelo Estado. A maior parte das despesas era suprida por meio de um convênio com a Legião Brasileira de Assistência (LBA), mas também existiam alunos pagantes: "A filosofia dos que fazem a Rosa Azul, merece ser ressaltada: quem tem condições paga, quem não tem não paga” (A ROSA AZUL. Tribuna de Aracaju, 1980 , p. 2). Muitos alunos assistidos pela instituição faziam parte de famílias consideradas carentes e, mesmo sem contribuírem financeiramente, a evasão desse público era grande, pois não tinham como pagar o transporte para chegar até o local.

Outra instituição, a Associação de Amigos do Autista de Sergipe (Amas) foi fundada na cidade de Aracaju, no ano de 1987, por um grupo formado por quatro famílias que tinham filhos diagnosticados com autismo. Essa instituição se dedicou exclusivamente à educação da pessoa com autismo, num período em que para muitos essa população ainda era considerada ineducável. Uma das fundadoras da instituição e sua primeira presidente, $\mathrm{MCr}$, informa que desde a sua fundação a Amas passou por vários endereços, a exemplo do conjunto Médici, no bairro Luzia, numa pequena casa alugada, e com o aparecimento de outras famílias com mais crianças com autismo tiveram que se mudar para uma casa maior no bairro Inácio Barbosa e, mais tarde, para uma casa na Vila Militar. Como tinham um terreno doado por um pai de aluno no bairro Coroa do Meio, ela conseguiu um auxílio financeiro junto à Corde ${ }^{1}$ e construiu nesse terreno a sede definitiva da Amas.

A Associação de Amigos do Autista de Sergipe, fundada no dia 20 de julho de 1987, teve, no dia 21 de agosto de 1987, empossada a sua primeira diretoria, bem como o seu conselho fiscal e consultivo (AMAS, Livro de atas..., 1987). Essa diretoria constituiu o primeiro estatuto $\mathrm{da}$ instituição, que a classificou como uma "Sociedade Civil de caráter assistencial e sem fins lucrativos", sendo proibida de distribuir lucros, dividendos ou bonificações aos seus membros e nem remuneração 
aos seus diretores e conselheiros. Esse documento também trazia que os objetivos da Amas eram dar assistência, promover e incentivar pesquisas e estudos sobre autismo, desenvolver programas de amparo, ajuda, adaptação, reabilitação e integração social, sem nenhuma forma de distinção. De acordo com esse estatuto, os recursos financeiros deveriam ser obtidos por meio de contribuiçóes periódicas dos sócios, mediante doações, subvenções, campanhas ou promoçóes destinadas ao levantamento de fundos. Os sócios contribuintes tinham por obrigação pagar pontualmente a contribuição periódica aprovada por assembleia geral, sendo que o não pagamento resultaria na sua exclusão (AMAS, Estatuto da..., 1987) ${ }^{2}$.

Neste trabalho, a educação é compreendida como processos formativos que ocorrem no meio social, nos quais as pessoas estão envolvidas de modo necessário e inevitável pelo fato de existirem socialmente (LIBÂNEO, 2013), sendo que as práticas educativas estão determinadas por exigências sociais, políticas e ideológicas, constituindo-se por conhecimentos definidos que irão inculcar condutas e normas com o objetivo de moldar os seres humanos segundo finalidades educacionais de determinado momento histórico-social.

No Centro de Reabilitação Ninota Garcia as pessoas com deficiência intelectual participavam das turmas do "Jardim de Infância", da "Escola Primária" e da "Escola Bertilde Carvalho", sendo que nas duas primeiras ficavam juntos com os alunos da comunidade que não tinha deficiência. De acordo com $\mathrm{MH}$, que foi diretora da instituição pelo período de dez anos, as instalaçôes físicas eram muito boas e atendiam a todas as necessidades da clientela. Eram atendidos alunos com todas as deficiências: visual, auditiva, intelectual e motora. "Então o objetivo era alcançar o maior êxito possível com aquelas pessoas que nos procuravam, dentro dos limites que existiam na época [...]" $(\mathrm{MH}$, 09/08/2011). A seleção das crianças era feita pelo pessoal responsável pela assistência social, e além desses, a instituição também contava com os serviços de um médico pediatra, um neurologista, um psicólogo e um fisioterapeuta. O diagnóstico era dado por esta equipe e depois era realizada uma triagem para o local onde o aluno deveria ser encaminhado.
Os alunos que frequentavam o "Ninota Garcia" tinham idades variadas. Existiam alunos com idades entre 15, 16, 18 e até 30 anos, o objetivo maior era a socialização. Com relação aos menores, além da socialização, eram trabalhadas atividades para coordenação motora, nomeação e distinção de objetos, classificação, seriação, agrupamento, leitura de histórias, escrita de letras e números, quantificação, desenho, pintura e noções básicas, como o conceito de maior e menor. Os alunos da "Escola Primária" estudavam vocabulário relacionado a palavras consideradas de uso no cotidiano, higiene e limpeza do corpo e do ambiente, comportamento social, datas comemorativas, noções de localização espacial, sistema monetário, verbos, caligrafia, leitura e noçốes matemáticas, como dúzia, metade, inteiro, composição e decomposição de números, dentre outros tópicos.

Sobre o seu trabalho na Apae, RM informa que a frequência dos alunos era boa. Eles dificilmente faltavam, e nas salas havia por volta de quatro alunos por turma, com um professor em cada uma delas. Os seus alunos eram jovens ou adultos, a maior parte com cerca de 20 anos de idade; todos diagnosticados com deficiência intelectual. Mas, segundo ela, tinha também uma turma de crianças menores, formada por alunos com uma faixa de sete anos de idade. RI foi aluno dessa professora, que relembra:

Tem muita história de RI. Eu lembro que estava grávida, com um barrigão e saía pelo corredor, correndo atrás de RI. A Apae era diferente, realmente, tanto na estrutura quanto nos atendimentos. Tinha psicólogo, eu corri para o psicólogo para pedir ajuda de como lidar com essas situaçôes (RM, 03/06/ 2019).

A clientela da Apae tinha suas turmas separadas por idade. De acordo com RM, sua prática pedagógica era realizada por meio de atividades que buscavam dar maior autonomia na vida diária de seus alunos, além de atividades que utilizavam as letras do nome, conceitos básicos de português e matemática, entre outras.

A instituição "Rosa Azul”, que foi criada com uma proposta multidisciplinar de trabalho, desde o início de seu funcionamento contou com a participação de diferentes tipos de profissionais, 
tanto do campo da saúde como no da educação. Assim como as outras instituições, essa também recebia professores da rede pública de ensino para atuarem junto aos seus alunos. Entre as primeiras docentes cedidas pelo Estado para trabalharem na "Rosa Azul” estava a professora MC. Ela entrou para a instituição no ano de 1981, nessa época instalada na avenida João Ribeiro. Nesse período não existiam no local pessoas com deficiências diferenciadas. A maioria do público tinha deficiência motora, principalmente oriunda da paralisia cerebral e ia fazer fisioterapia. Com o tempo, a instituição passou a ser conhecida pela sociedade e outras pessoas começaram a chegar, muitas das quais tinham síndrome de Down.

No período em que as instalaçốes estavam na "Chácara Asa Branca", no ano de 1985, a professora MC considerava-as razoáveis, pois as salas eram adaptadas, visto que era uma chácara e antes existiam cocheiras e a área livre era muito espaçosa e ventilada. LM, que nessa época era funcionária contratada pela instituição e trabalhava no setor administrativo, confirma essas informaçóes e complementa:

Eram seis salas abertas, tinha havido cavalos no lugar, aí CC fez um muro e transformou em salas. Tinha uma casa atrás que era a administração e outra mais à direita que era onde se fazia fisioterapia” (LM, 28/05/2019).

LM também foi pedagoga na Apae, antes de trabalhar na "Rosa Azul", e informa que o trabalho nas duas instituiçóes era bem parecido.

Depois de pouco tempo trabalhando como docente, MC assumiu a função de coordenadora pedagógica na instituição, e, segundo ela, eram poucos alunos por turma, no máximo entre oito e dez, cada sala tinha a presença de uma professora e uma auxiliar, e os discentes eram separados por idade e por deficiência. Nessa fase eram atendidas pessoas com deficiências auditiva e intelectual e com relação às idades eram "[...] de zero até quando eles não queriam mais" (MC, 28/05/2019). Para os pequeninos, entre zero e quatro anos de idade, existia um trabalho de estimulação precoce e estimulação essencial. Esse trabalho compreendia atividades, recursos humanos e ambientes incentivadores que visavam proporcionar às crianças, nos seus primeiros anos de vida, experiências que as possibilitassem alcançar um desenvolvimento pleno no seu processo evolutivo.

A Amas realizava atividades de alfabetização para pessoas com autismo leve e que estudavam no ensino regular, mas que precisavam desse apoio no contraturno para se desenvolver de modo mais adequado. Com essas pessoas, as atividades pedagógicas eram organizadas da seguinte forma:

Uma coisa bem maternal mesmo, cobrir letrinha, para isso às vezes era necessário segurar na mão, a questão do equilíbrio com o trabalho com obstáculos, reconhecimento de objetos concretos, formas, encaixes. Tinha um trabalho também com alinhavos, pinturas livres e com moldes vazados em panos de prato, lençóis, ponto de cruz, esculturas, tapeçarias, bijuterias, aquelas coisas todas que a gente fazia e vendia nas feiras. Esse trabalho também era realizado com os alunos com autismo mais severo, mas eles precisavam de mais ajuda. À medida que eles iam crescendo a gente ia fazendo coisas mais condizentes com as idades. Eu me lembro que uma vez que nós fizemos um ovo de páscoa, alguns fizeram sozinhos, outros com a gente, foi uma ‘sensação’ para eles (MCr, 04/04/2019).

Com esse trabalho as docentes percebiam uma evolução nos alunos e informam que não recebiam muitos deles na instituição, pois preferiam trabalhar se preocupando com a qualidade e não com a quantidade. Outros alunos, com autismo severo, ficavam o dia inteiro na instituição e nela tinham tanto a hora do sono quanto da escovação, todos esses momentos eram oportunidades de grande aprendizado.

Os professores das instituiçôes pesquisadas relataram que sempre participavam de cursos relacionados à questão da deficiência promovidos pelas instituições, pelo Estado ou pelos municípios, sendo muitos deles ministrados por profissionais de destaque nacional. A promoção destes, pelo poder público, se deve ao fato de que a maioria dos professores que trabalhavam nessas instituiçóes era do quadro de docentes da educação pública, os quais eram cedidos a essas instituiçôes, como já foi citado anteriormente.

De acordo com professores do "Ninota Garcia” esses cursos eram constantes, contudo, de modo diferente relatam as professoras que 
trabalharam na Apae, essas afirmaram que participavam de cursos, mas que estes não eram regulares. Constantes ou inconstantes, a presença desses cursos demonstra que os profissionais recebiam qualificação para exercer o seu trabalho. $\mathrm{O}$ problema fica no fato de que a maioria dos docentes trouxe a informação de que nesses cursos eram abordados conceitos sobre as deficiências e não apresentavam metodologias que pudessem dar um direcionamento para o trabalho junto aos alunos com deficiência, na sala de aula. Por conta disso, muitas professoras afirmaram que passaram a conhecer mais as deficiências, porém o trabalho não tinha um direcionamento metodológico, era pautado nas intuições pessoais. "Era um trabalho intuitivo, de acerto e erro. A gente partia do que o aluno sabia fazer, do que ele era capaz. Hoje a gente chama de currículo individual do aluno" (VM, 06/05/2019).

Desse mesmo modo intuitivo de direcionar o trabalho pedagógico atuava a professora MA. Ela fez parte do grupo das primeiras professoras da Amas e se emocionou muito durante toda a sua narrativa, relembrando seu trabalho nessa instituição. Apesar de classificar seu trabalho como intuitivo, a instituição contava com o apoio de profissionais como fonoaudiólogos, terapeutas ocupacionais, psicólogos, fisioterapeutas e alguns médicos que orientavam o trabalho realizado. Neste sentido, com relação à qualificação, a professora $\mathrm{VM}$ relata que a Amas, desde o seu início, forneceu um assessoramento muito bom, tendo o cuidado de buscar informaçóes com um referencial teórico e clínico por meio de médicos de renome nacional na área do autismo. Porém, esse é um público muito difícil de se trabalhar, pois as variações dentro do transtorno são inúmeras. Se analisarmos os profissionais citados pelas professoras, perceberemos que era um apoio de conhecimento clínico, todos atuantes na área da saúde, o que talvez justifique esse trabalho pautado na intuição, demonstrando uma lacuna nos conhecimentos de cunho pedagógico.

A partir dos relatos das professoras que trabalhavam nas instituições pesquisadas e dos outros documentos analisados, foi possível a construção do Quadro 1, acerca das práticas educacionais que eram realizadas. Nele observa-se que as atividades desenvolvidas nas instituiçóes eram bastante semelhantes, sendo que a maioria dessas atividades favorecia o desenvolvimento das habilidades motoras. O trabalho direcionado à matemática se referia aos conceitos básicos e quanto a uma prática voltada para a alfabetização, entendida como competência para ler e escrever, essa também ficava apenas na escrita de letras do alfabeto e do nome próprio, o que torna uma experiência muito limitada para se alcançar este objetivo. A única que citou a contação de histórias foi uma professora do Ninota Garcia, o que não significa que esta prática não era realizada nas outras instituiçôes. Em todos os locais pesquisados o trabalho de socialização foi citado como desenvolvido por meio de festas comemorativas internas e passeios externos, não sendo descrita nenhuma atividade cotidiana para este fim. No que diz respeito à construção da autonomia, o que mais se utilizava era o ensinamento de como cuidar do próprio corpo, apenas as professoras da Amas, neste quesito, mencionaram a estimulação sensorial e o desenvolvimento da percepção visual como formas de propiciar tal habilidade.

A falta de conhecimento metodológico e a escolha deste referido modelo "intuitivo" de se ensinar também podem ter como explicação o fato já relatado de que a maior parte das professoras entrevistadas tinha, no período retratado na pesquisa, formação apenas em nível médio. Além disso, as outras entrevistadas estavam iniciando o curso superior em Pedagogia ou tinham acabado de se formar nesse curso. Concomitantemente, para a maioria destas, era a primeira experiência docente, e já com pessoas com deficiência, sendo que essas comumente necessitam de métodos de ensino adequados às suas especificidades. Então, foram aprendendo seu ofício, na prática do "fazer pedagógico". 
Quadro 1 - Práticas ed ucacionais desenvolvidas nas instituições pesquisadas

\begin{tabular}{|c|c|c|}
\hline No & Instituição & Práticas Pedagógicas \\
\hline 01 & $\begin{array}{c}\text { Centro de Reabilitação } \\
\text { Ninota Garcia }\end{array}$ & $\begin{array}{l}\text { - Atividades de coordenaçãa motora - desenho e pintura. } \\
\text { - Noções básicas de português - nomeação e distinção de objetos, contação de histórias e } \\
\text { escrita de letras. } \\
\text { - Noções básicas de matemática - seriação, agrupamento, classificação, quantificação de } \\
\text { elementos, localização espacial e escrita de números. } \\
\text { - Atividades de socialização - festas comemorativas internas. } \\
\text { - Atividades para desenvolvimento da autonomia - cuidados com o corpo e o ambiente. }\end{array}$ \\
\hline 02 & $\begin{array}{l}\text { Sociedade de Ensino e } \\
\text { Reabilitação Rosa Azul }\end{array}$ & $\begin{array}{l}\text { - Atividades de coordenação motora - desenho, colagem, pintura, alinhavo e modelagem. } \\
\text { - Noçóes básicas de português - vocabulário de palavras de uso cotidiano e escrita do nome e } \\
\text { das letras do alfabeto. } \\
\text { - Noçóes básicas de matemática - quantificação de elementos, escrita de números e cores. } \\
\text { - Atividades de socialização - passeios externos e festas comemorativas internas. } \\
\text { - Atividades para desenvolvimento da autonomia - cuidados com o corpo. }\end{array}$ \\
\hline 03 & $\begin{array}{c}\text { Associação de Pais e Amigos } \\
\text { do Excepcional - Aracaju }\end{array}$ & $\begin{array}{l}\text { - Atividades de coordenação motora - desenho, pintura e colagem. } \\
\text { - Noções básicas de português - atividades com as letras do nome. } \\
\text { - Noções básicas de matemática - quantificação de elementos e cores. } \\
\text { - Atividades de socialização - passeios externos e festas comemorativas internas. } \\
\text { - Atividades para desenvolvimento da autonomia - cuidados com o corpo. }\end{array}$ \\
\hline 04 & $\begin{array}{l}\text { Associação de Amigos do } \\
\text { Autista de Sergipe }\end{array}$ & $\begin{array}{l}\text { - Atividades de coordenação motora - encaixes, alinhavos, pinturas, confecção de bijuterias e } \\
\text { esculturas. } \\
\text { - Noçôes básicas de português - vocabulário com o nome de objetos concretos e escrita das } \\
\text { letras do alfabeto. } \\
\text { - Noçôes básicas de matemática - quantificação de elementos, seriação, agrupamento e cores. } \\
\text { - Atividades de socialização - passeios externos e festas comemorativas internas. } \\
\text { - Atividades para desenvolvimento da autonomia - estimulação sensorial e percepção visual. }\end{array}$ \\
\hline
\end{tabular}

Fonte: Elaborado pelos autores (2020).

Necessário destacar que no Brasil, só a partir dos anos de 1950 começaram a ser implementadas iniciativas oficiais voltadas para a educação desta parte da população. Essas se iniciam por meio das chamadas "Campanhas", tendo a primeira ocorrida no ano de 1957, com a finalidade de promover educação e assistência às pessoas surdas. A partir de então outras foram sendo instituídas, voltadas para outros tipos de deficiências. Essas campanhas foram importantes pois possibilitaram a realização de diversos encontros em que foram discutidas questôes relacionadas à educação das pessoas com deficiência. As Campanhas Nacionais foram extintas no ano de 1973, quando o então presidente Emílio Garrastazu Médici (1969-1974) cria o Centro Nacional de Educação Especial (Cenesp), com o objetivo de organizar a Educação Especial brasileira (BUENO, 2016).

Segundo Iara Maria Campelo Lima, uma das responsáveis pela implantação da Educação Especial no estado de Sergipe, o trabalho pedagógico orientado pelo Cenesp era mais voltado para a psicomotricidade, conhecida na época como "prontidão". Essa é uma atividade importante no início da prática educativa, mas de modo muito lúcido Iara nos traz que: "Tudo isso é importante, mas não saía daí. Tem que dar outros tipos de oportunidades. O problema era a dificuldade de as pessoas acreditarem na capacidade de superaçáa”" (LIMA, 14/05/2019). Importante repetir que ao se observar o Quadro 1, além das atividades psicomotoras, as instituições pesquisadas trabalhavam apenas com as noçóes básicas de português, matemática e atividades que visavam socialização e autonomia relacionada aos cuidados com o próprio corpo. Neste sentido, percebe-se que a incredibilidade quanto ao potencial das pessoas com deficiência impunha limites na oferta de possibilidades de uma educação de qualidade, uma 
educação que lhes propiciasse real condição de êxito no campo educacional.

Possivelmente esta visão limitada e limitante, além da já mencionada influência médica, propiciava o formato dos cursos oferecidos aos professores que atuavam na educação especial, que se preocupava mais com questóes orgânicas do que educacionais. $\mathrm{O}$ que deixava uma lacuna nos conhecimentos necessários a uma prática educacional teoricamente embasada.

\section{Considerações finais}

Ao estudar a história das práticas educacionais direcionadas às pessoas com deficiência no estado de Sergipe, entre os anos de 1962 e 1987 nas instituiçôes pesquisadas, percebe-se inicialmente que essas práticas ocorriam, na maioria dos casos, pautadas num modelo denominado pelas professoras de "intuitivo", sendo que a partir dos resultados obtidos iam dando direcionamento aos seus trabalhos.

Quanto às práticas educacionais desenvolvidas, o que mais se observou foi a primazia de atividades relacionadas, principalmente, à coordenação motora e conceitos básicos de português e matemática. Esses ensinamentos, talvez por conta do grau de deficiência intelectual presente nos alunos ou pela falta de credibilidade dada às suas possibilidades de êxito educacional, eram sempre num nível inicial, o que não se configurava como uma prática voltada para a alfabetização. Deste modo, faz-se relevante salientar que da mesma forma que não se pode limitar a capacidade de uma pessoa aprender, também não se deve exigir que ela adquira conhecimentos que, em determinado momento, não sejam compatíveis com as limitaçóes que apresente. No que se refere à relação com um currículo formal, alguns trabalhos desenvolvidos nas instituições eram similares aos realizados nos anos iniciais das escolas regulares, contudo não avançavam para atividades que exigissem um nível maior de complexidade.

O fato é que apesar das lacunas existentes, no que se refere a um trabalho pedagógico que estimulasse ao máximo o potencial dos alunos atendidos, num período de muita desinformação e de pouca circulação das informaçóes que existiam, essas instituiçốes receberam muitas pessoas com deficiência e, a partir do que sabiam e do que iam aprendendo nos cursos que participavam e do contato com os próprios alunos assistidos, seus profissionais contribuíram para que essas pessoas pudessem se desenvolver por meio de todos os estímulos possíveis de serem dados no período pesquisado.

\section{Notas}

1 "O interesse público em relação aos direitos das pessoas com deficiência foi reconhecido na estrutura do Estado brasileiro com a criação da Coordenadoria Nacional para Integração da Pessoa Portadora de Deficiência (CORDE), em 1985 [...] A criação da CORDE significou um passo importante na ação governamental voltada para os direitos da pessoa com deficiência. Até então, o Estado brasileiro promovia apenas açóes setoriais, como as campanhas voltadas para a educação especial que remontam à década de 1950” (LANNA JÚNIOR, 2011, p. 01).

$2 \mathrm{Na}$ Amas foram encontrados poucos documentos. Além desse estatuto e do termo de posse, foram encontradas duas atas, a primeira tratava da eleição da primeira diretoria, datada de 03/08/1987, e a segunda abordava destituição de membros da diretoria e do conselho fiscal. Esses documentos, apesar de legíveis, não se encontravam em bom estado de conservação. Quando questionados sobre a situação destes e sobre a ausência de outros, a informação obtida, por meio do atual secretário, é de que todos foram perdidos decorrentes de uma chuva que causou muitos danos à instituição e destruiu os documentos lá existentes. Não foi encontrado nenhum registro iconográfico.

\section{Referências}

AMAS, ASSOCIAÇÃO DE AMIGOS DO AUTISTA DE SERGIPE. Estatuto da Associação de Amigos do Autista de Sergipe. 1987.

AMAS, ASSOCIAÇÃO DE AMIGOS DO AUTISTA DE SERGIPE. Livro de Atas da Associação de Amigos do Autista de Sergipe. 1987. 
A ROSA AZUL. Tribuna de Aracaju, № 2.139, Ano X, 09 de agosto de 1980.

BUENO, José Geraldo Silveira. Educação especial brasileira: questôes conceituais e de atualidade. São Paulo: EDUC, 2016.

CC. 2019. Entrevista concedida a Walna Patrícia de Oliveira Andrade. Aracaju. 23.05.2019.

CHARTIER, Roger. A história cultural: entre práticas e representaçóes. Trad. Maria Manuela Gualhardo. Lisboa: Difusão Editora, 1988.

EDUCAÇÃO de excepcionais. Diário de Aracaju, 13 de agosto de 1980.

GARCIA FILHO, Antônio. A reabilitação em Sergipe. Aracaju: Gráfica Aracaju, 1966.

GOFFMAN, Erving. Estigma: notas sobre a manipulação da identidade deteriorada. Trad. Mathias Lambert. Rio de Janeiro: LTC, 1988.

INAUGURADO festivamente o Centro de Reabilitação "Ninota Garcia”. Correio de Aracaju, № 6. 743, Ano LV, 27 de junho de 1962.

JANNUZZI, Gilberta de Martino. A ed ucação do deficiente no Brasil: dos primórdios ao início do século XXI. Campinas, SP: Autores Associados, 2012.

LANNA JÚNIOR, Mário Cléber Martins. A CORDE e o CONADE na organização administrativa do Estado brasileiro. Disponível em:

$<$ http://www.bengalalegal.com/corde-historia-pcd>. Acesso em: 16 jul. 2019.
LIBÂNEO, José Carlos. Didática. São Paulo: Cortez, 2013.

LIMA, Iara Maria Campelo. 2019. Entrevista concedida a Walna Patrícia de Oliveira Andrade. Aracaju. 14.05.2019.

LM. 2019. Entrevista concedida a Walna Patrícia de Oliveira Andrade. Aracaju. 28.05.2019.

MAgAlHÃes, Ana Cristina et al. Pais e dirigentes: uma parceria eficiente. Reflexôes sobre a interpelação entre família e instituição na vida da pessoa portadora de deficiência. Brasília: Federação Nacional das APAEs, 1997.

MA. Entrevista concedida a Walna Patrícia de Oliveira Andrade. Aracaju. 11.06.2019.

MC. 2019. Entrevista concedida a Walna Patrícia de Oliveira Andrade. Aracaju. 11.06.2019.

MCr. 2019. Entrevista concedida a Walna Patrícia de Oliveira Andrade. 04.04.2019.

MEIHY, José Carlos Sebe Bom; HOLANDA, Fabíola. História oral: Como fazer, como pensar. São Paulo: Contexto, 2007.

MENDONÇA, Ana Cláudia Sousa; SOUZA, Rita de Cácia Santos. Associação de Pais e Amigos dos Excepcionais (APAE) - Aracaju: formação de professores e práticas educativas (1968-1988). Aracaju: Criação, 2018.

MH. 2011. Entrevista concedida a Patrícia de Sousa Nunes Silva. Aracaju. 09.08.2011. 
MINATEL, Martha Morais. Institucionalização e educabilidade da infância anormal em Sergipe (1940-1979). 2018. Tese (Doutorado em Educação) - Universidade Federal de Sergipe, São Cristóvão, 2018.

RM. 2019. Entrevista concedida a Walna Patrícia de Oliveira Andrade. Aracaju. 03.07.2019.

SILVA, Laís Marta Alves da; RODRIGUES, Fernanda Plaza. A Escola normal e as reformas ed ucacionais como símbolo republicano. 2018. Disponível em:

https://sigeve.ead.unesp.br/index.php/submission/d ownloadFileProceedings/2349. Acesso em: 19 mar. 2021.

SILVA, Patrícia de Sousa Nunes. Antônio Garcia Filho (1941-1999): um intelectual engajado. 2012. Dissertação (Mestrado em Educação) - Unit, Aracaju, 2012.

SOUZA, Rita de Cássia Santos. Educação Especial em Sergipe: uma trajetória de descasos, lutas dores e conquistas. Dissertação (Mestrado em Educação) UFS/São Cristóvão - SE, 2000.

VM. 2019. Entrevista concedida a Walna Patrícia de Oliveira Andrade. Aracaju. 06.05.2019.

VYGOTSKY, L. S. Obras escogidas: tomo V. Fundamentos de defectologia. Madrid: Espanha: Visor, 1997. 